\title{
SBQ PRODUCTION WITH OPTIMIZED MACHINERY DESIGN AND PROCESS PARAMETERS OF THE 3-ROLL RSB SCS ${ }^{\circledR *}$
}

Patrick Edward Connell ${ }^{1}$ Sergio Antonio Filippini ${ }^{2}$ Glyn David Ellis ${ }^{3}$

\begin{abstract}
The next generation of the well-established 3-roll Reducing \& Sizing Block (RSB), the RSB SCS ${ }^{\circledR}$ is the latest milestone in reducing and sizing technology for SBQ products. It offers enhanced bar quality, improved productivity, mill availability and economy as well as a simplified, safe and environmentally friendly operation. A newly developed modular drive concept of the RSB SCS ${ }^{\circledR}$ grants a smaller footprint in the layout, a reduced oil-lubrication volume and a simplified maintenance schedule. Intelligent engineering leads furthermore to reduced hydraulic functions of the RSB $\mathrm{SCS}^{\circledR}$, which ensures a safe and environmentally friendly rolling. Another integral part of the RSB SCS ${ }^{\circledR}$ is an innovative stand changing concept, which allows automatic stand changing within three minutes. The new RSB SCS ${ }^{\circledR}$ also includes a Fast Remote Control (FRC) which enables the immediate adjustment of the roll gap against the rolling force (under load) within milliseconds. Size changes along the free-size range can also be made within the traditional billet gaps in less than five seconds. At the core of the future-oriented $\mathrm{RSB} \mathrm{SCS}^{\circledR}$ is a real-time closed-loop control system called Size Control System (SCS $\left.{ }^{\circledR}\right)$ acting with 3-roll stands adjustable under load (AUL) and / or the heavy duty stands. These features remarkably further improve the rolled tolerances and their reproducibility, and at the same time simplify the operation by means of an automated optimization of the process parameters for the rolled bars.
\end{abstract}

Keywords: Size control; Closed-loop control; Reducing \& Sizing Block; RSB SCS ${ }^{\circledR}$. 


\section{INTRODUCTION}

In 1979, the first 3-roll Precision Sizing Block [PSB] was installed at today's Deutsche Edelstahlwerke, Siegen / Germany. The benefits at the time included, tightest tolerances, superb metallurgical properties and excellent surface qualities. Over time, it was realized that in addition to the quality benefits, there was also a resulting increase in yield, mill availability, and reduced conversion costs. All of these attributes became associated with Friedrich Kocks GmbH \& Co KG.

The brand "KOCKS" is the industry standard when discussing 3-roll technology for wire rod and bar sizing. It represents the leading technology in the SBQ bar market. More than 32 million tons per year of straight bars, bar in coil and wire rod are rolled each year on 86 blocks with 3-roll RSB ${ }^{\circledR}$ technology.

As a trusted resource for the increasingly demanding SBQ market - mainly driven by the automotive industry, in which internal quality requirements often exceed the published standards - Kocks has established many pioneering innovations to further improve the valued performance of the 3-roll RSB ${ }^{\circledR}$ technology.

The next generation of the 3-roll Reducing \& Sizing Block RSB ${ }^{\circledR}$, the RSB SCS ${ }^{\circledR}$, is the latest milestone in reducing and sizing technology for SBQ products.

By utilizing a cooperative and constant dialogue with our customers and consumers of SBQ steel products, innovative new concepts were incorporated into the RSB SCS $^{\circledR}$. These innovations are a strong response to the latest stringent demands of the SBQ market.

They will help OEM and their suppliers to be prepared for future competitive pressures by granting enhanced bar quality, improved

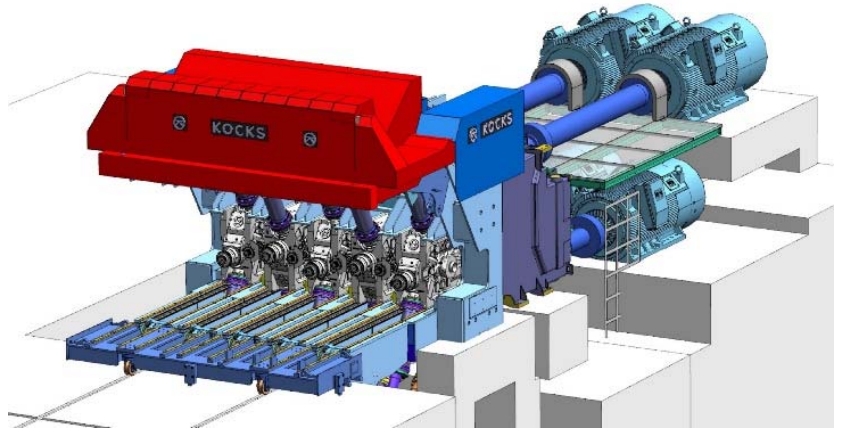

Figure 1: 3-roll RSB SCS ${ }^{\circledR}$

productivity, mill availability and economy as well as a simplified, safe, and environmentally friendly operation with a high automation degree.

\subsection{Motivation for the Development of the New RSB SCS $®$}

The RSB ${ }^{\circledR}$ has long been known as a work-horse in SBQ steel bar production. "First bar in tolerance" is a known and understood catch phrase when discussing Kocks bar sizing equipment. But the market is an ever changing place. Constant requirements to improve quality, increase production and lower costs force product improvement at an unrelenting pace. The message from the marketplace is clear, improve or be replaced.

In response to these market forces, Kocks has made changes that have reinforced its image as a market innovator.

Features of the new $\mathrm{RSB}^{\circledR}$ include: 


\subsection{Increased Production}

By adding features that allow higher production, while conversion and operating costs/ton are greatly reduced. By improving the productivity and availability of the mill when operating with the RSB ${ }^{\circledR}$ all of these benefits are achieved.

The level of mill availability and productivity has been greatly enhanced on the new RSB SCS ${ }^{\circledR}$ by means of a dynamic new stand changing system. This system allows stand changes in as little as three minutes from mill stop to mill start. Mill delays for size change or pass wear can be reduced to almost negligible levels. The resulting production increase can justify significant investment as a stand alone line item.

In addition to a fast stand change, many size changes are accomplished using only stand adjustment. The new Fast Electric Remote Control can adjust the pass for size or pass wear in milli-seconds. Now small adjustments or free-size adjustments up to $3 \mathrm{~mm}$ can be accomplished in the shortest billet gap. This allows precise operation of the mill. No question of whether to stop to make an adjustment. Quality is enhanced with zero resultant decrease in production.

\subsection{Making Tolerance Repeatable}

The requirement to produce a consistent superb finished quality is the result of a push to reduce handling effort, as well as time-consuming sorting. With today's highly automated machining and forging processes, there is no room for variability.

The RSB ${ }^{\circledR}$ technology is capable of producing at tolerance levels that can achieve 1/7 DIN or better. The challenge of this ability is to make the process repeatable regardless of operating variables. The result of this drive for consistency has resulted in the development of the Size Control System SCS ${ }^{\circledR}$.

\subsection{Highlights of the New RSB SCS ${ }^{\circledR}$}

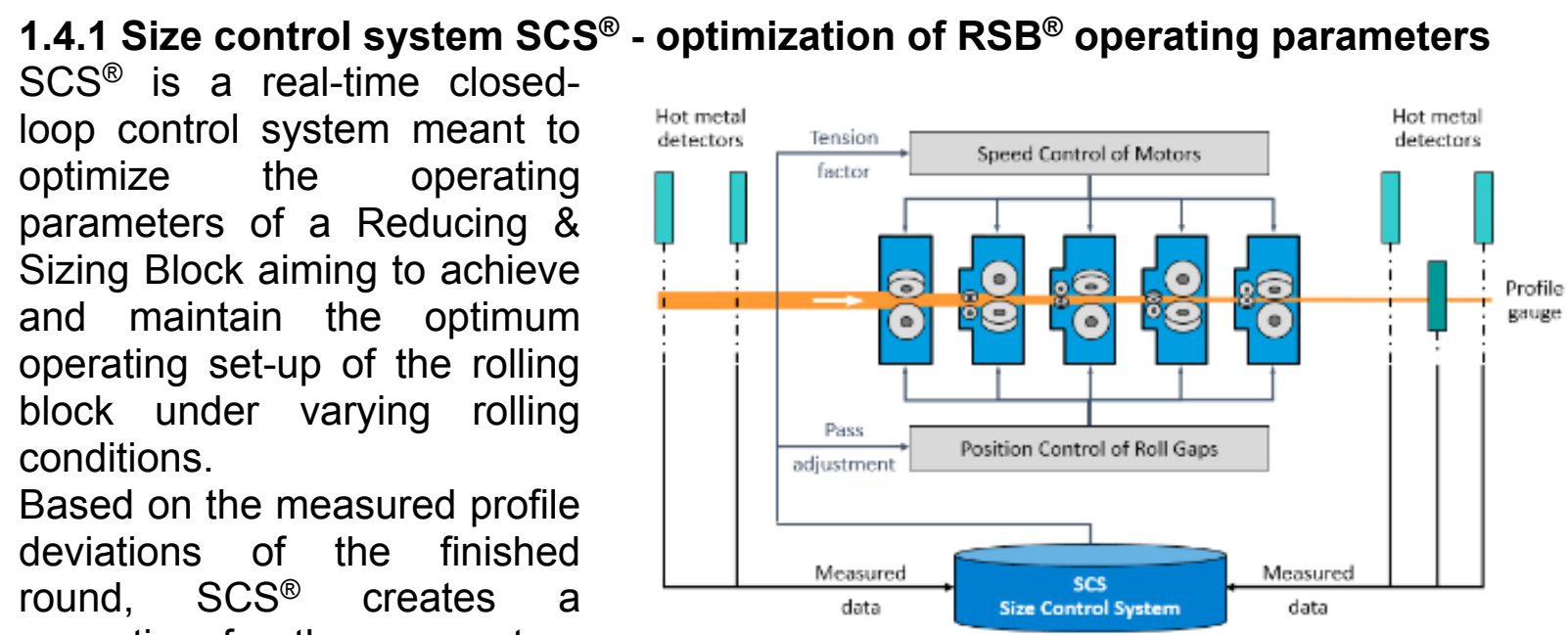
correction for the parameters 'pass size' or 'motor speed' for the stands in the RSB ${ }^{\circledR}$.

Figure 2: Layout Size Control System SCS ${ }^{\circledR}$

SCS $^{\circledR}$ significantly improves the conventional position and speed control of the RSB ${ }^{\circledR}$, immediately adapting these two operating parameters for every stand in case of deviations of the finished round. 
Pass adjustment can be performed immediately during rolling for stands with "Adjustment Under Load" (AUL) or during billet gaps of less than one second.

Speed Control done through the modification of the tension factor can be applied to improve the size tolerance immediately while the bar is being rolled. Roll wear can also be easily compensated by $\mathrm{SCS}^{\circledR}$ without interrupting the production, maintaining the optimum tolerance level all the time.

Moreover, another accomplishment was to incorporate a software system able to register, visualize and save selected process data from the mill line and to analyze and evaluate the recorded process data. This software allows process adjustment for future rolling campaigns based on actual performance today.

The addition of extremely precise process optimization has also had the unexpected benefit of greatly reducing new mill start-up time. By reliably predicting correct set-up during commissioning, new operators are able to confidently operate the $\mathrm{RSB}^{\circledR}$ at a level approaching an experienced operator. This allows immediate production of profit creating equipment.

\subsection{Stands Adjustable Under Load (AUL)}

SCS $^{\circledR}$ operates either with stands adjustable under load (AUL) or with conventional stands (flange type or "heavy duty" design).

The stand adjustable under load (AUL) is able to adjust the roll pass during the rolling process against the rolling force. The three rolls move concentrically against the rolling force to achieve the optimum pass size.

By taking closed-loop feedback from the SCS $^{\circledR}$, the stands are opened or closed to achieve tight tolerance or to reduce the effects of pass wear on the bar. These stands, based on the proven 3roll heavy-duty stands, can be inserted into an existing $\mathrm{RSB}^{\circledR}$.

\subsection{Fast Pass Adjustment}

Without an extremely fast remote control, the proven benefits of SCS and AUL would be greatly limited. For this reason, the newly developed Fast Remote Control was integrated as an integral part of the new $\mathrm{RSB}^{\circledR}$ generation.

The well-proven remote control of stands and guides was re-designed and further optimized in order to cope with the need for faster size changes.

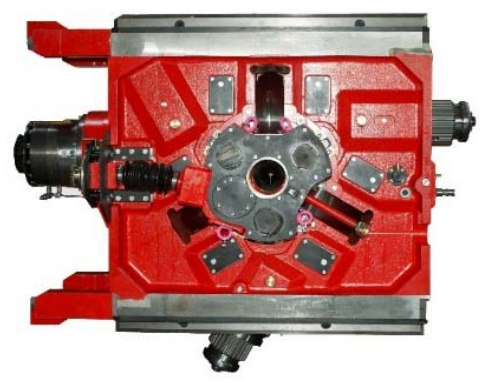

Figure 3: Stand Adjustable Under Load (AUL)

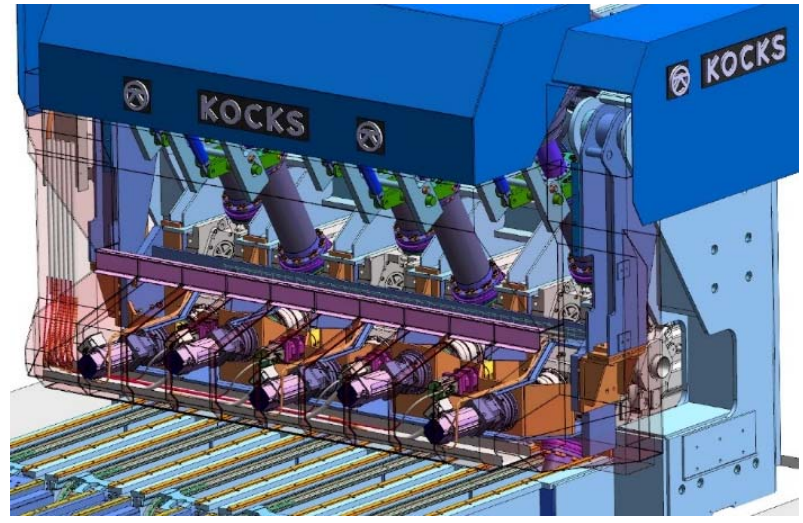

Figure 4: New Fast Remote Control (FRC)

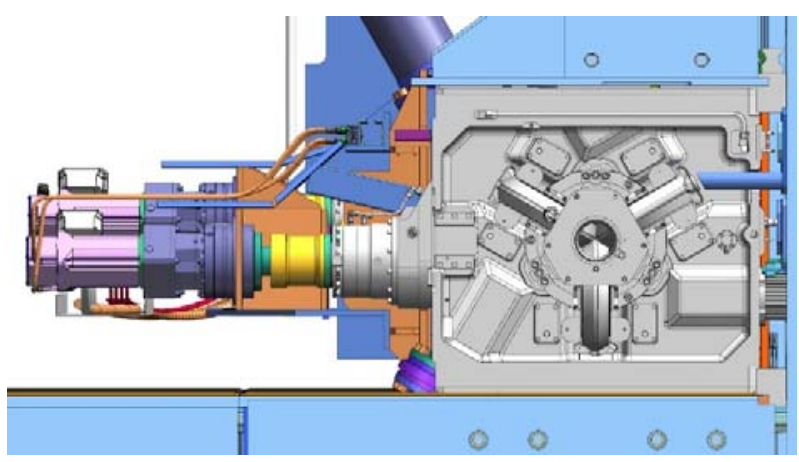

Figure 5: Cross Section of the FRC 
Free-size adjustments can be done without stand change in a traditional billet gap of less than five seconds. With AUL stands, these adjustments can be undertaken immediately against the rolling force in milli-seconds, maintaining excellent finished tolerances with absolutely no break in production.

These adjustments are made individually for every stand and roller guide. This is accomplished by means of a set of servo-motors, situated inside the safety cover of the $\mathrm{RSB}^{\circledR}$. The coupling of the remote control drives occurs automatically when the safety cover is closed.

In addition to fast pass adjustment, no modern mill could operate with less than the fastest stand change time. An integral part of the new $\mathrm{RSB}^{\circledR}$ generation is an innovative stand changing concept, which allows a complete size change in less than 3 minutes.

\subsection{Fast Stand Changing}

This fully automated system allows each stand to be individually pulled out or pushed into the pass line by an electrically operated chain system, which is integrated in the stand base. The stand cars are equipped with a toggle operated safety bar, which assures that the stands are positioned correctly on the car.

No other sizing system can offer such a quick stand changing system. This new leap forward, like the others described above, lead to high mill availability and

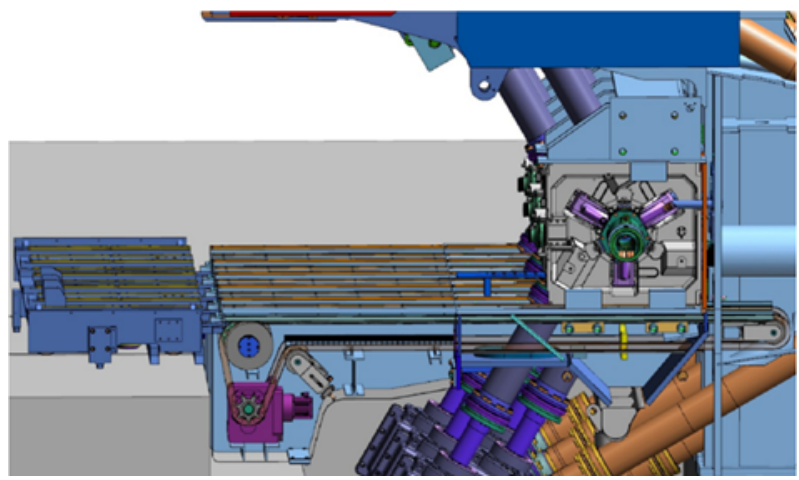

Figure 6: Fast stand changing concept corresponding increased profitability.

\subsection{New Drive Concept}

A market requirement that has become more and more critical over time has been the need to reduce overall project cost. The well-respected C-module design that Kocks has pioneered is proven as a reliable and long lasting drive-train. The only downside to this technology is the space that is required to install the equipment and its resulting cost.

The challenge of this development was to develop a drive train that not only reduces project cost, but actually improves on existing technology. The result of this design effort is the newly developed modular drive concept of the RSB SCS ${ }^{\circledR}$. By integrating the reduction gears and the driving gears into one gear box, a much smaller foot print is realized. This allows installation of the equipment in smaller existing spaces or new buildings. Ultimately leading to

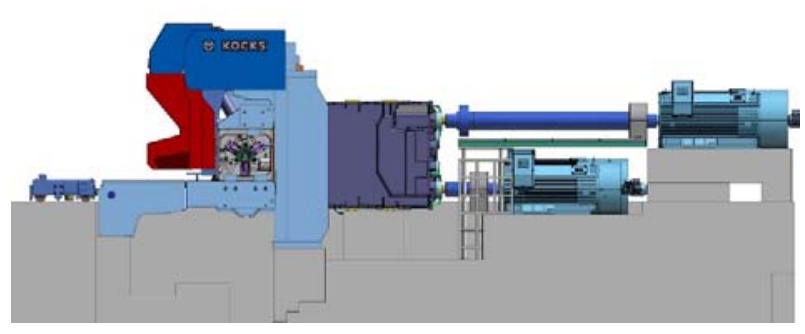

Figure 7: Drive train RSB SCS ${ }^{\circledR}$ 
reduced costs.

Finally, less gears in the drive train lead to a drastically reduced oil-lubrication volume and less requirements for spare parts. The reduced number of gears and maintenance free drive shafts, which require no lubrication at all, result in a simplified maintenance.

\subsection{Rolling Results with SCS $®$ and AUL}

All of the design updates undertaken over the last years have resulted in a reducing and sizing mill that is capable of greatly improved operations and maintenance. But without resulting improvements in actual production, the accomplishment would be diluted. In order to prove that the technical concepts are sound and reliable, Kocks has undertaken extensive trials with producers who are among the most demanding in the marketplace.

An example of these trials were taken from the reputable German SBQ-producer Georgsmarienhütte $\mathrm{GmbH}$, where the $\mathrm{SCS}^{\circledR}$ is successfully in operation since the summer shutdown of 2012.

Making use of the "free-size" pass design it is a daily routine to roll stable and reproducible tolerance and ovality values, which are consistently within 1/10 DIN EN 10060.

The following example underlines the ability of the size control system SCS ${ }^{\circledR}$ :

44 bars with the finished target size of $\mathrm{rd}$. $55.2 \mathrm{~mm}$ were rolled at $\mathrm{GMH}$ with different material grades, different spreading characteristics and different temperatures.

The results showed a total ovality level better than $1 / 7$ DIN EN 10060 covering all 44 bars and better than 1/12 DIN EN 10060 for individual bars

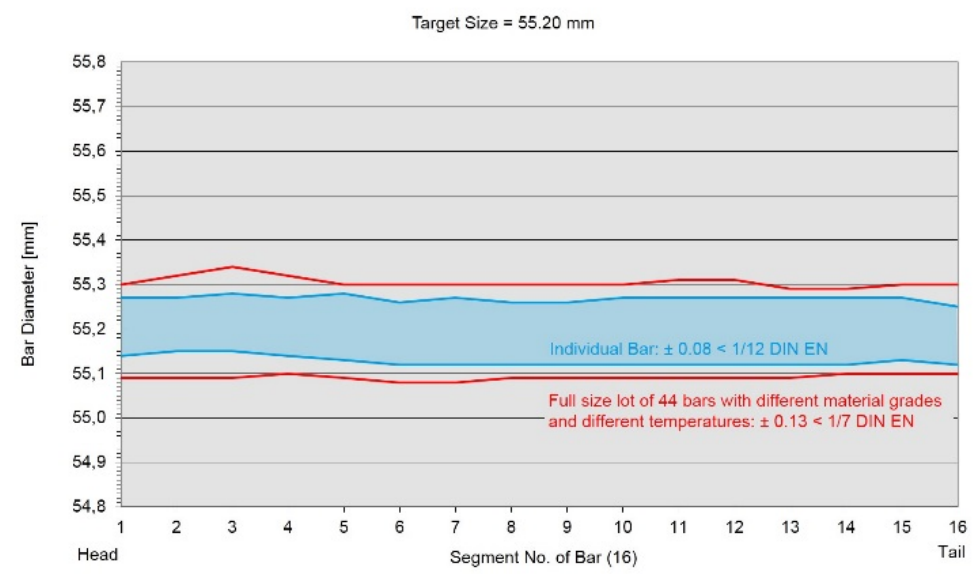

Figure 8: Rolling results at $\mathrm{GMH}$ within the rolled lot.

These results, achieved when using $\mathrm{SCS}^{\circledR}$ and $\mathrm{AUL}$, validate the design principles that Kocks is presenting to the market, producing near perfect quality in increasing volumes.

\section{CONCLUSION}

The RSB SCS ${ }^{\circledR}$ allows the operator to produce a finished product which is highly competitive and well above the expectations of the automotive and engineering industry.

The new RSB SCS ${ }^{\circledR}$ is the perfect response to an increasingly challenging market that requires companies to meet current and future customer demands successfully. Summarizing, the new $\mathrm{RSB}^{\mathrm{SCS}}{ }^{\circledR}$ allows every SBQ mill to produce a highly competitive product with the lowest possible conversion costs.

$\mathrm{RSB}^{\circledR}$ and $\mathrm{SCS}^{\circledR}$ are German trademarks, registered by Kocks 


\section{BIBLIOGRAPHY}

1 Dewald, O.; Ullrich, G.; Kruse, M.: Controlled under load. New automation system for the reducing \& sizing block; MPT International 2011, No.3, P. 124-127

2 Golinske, K., Schliephake, H.; Schwarz, S.: Modernization of the SBQ bar mill at Georgsmarien-hütte, Germany, MPT International, 2013, No. 3, P. 40-45

3 Schwarz, S.; Ammerling, W.-J.; von der Heiden, J.: Application of the KOCKS 3-roll technology, presented at SEAISI Conference 2010 in Ho Chi Min City / Vietnam, 17.19.05.2010, published on the proceedings CD-ROM as PDF file. 